\title{
ESTUDO DE CASO: PARCERIA COOXUPÉ/NESPRESSO NO CERRADO MINEIRO ${ }^{1}$
}

\author{
CRUZ, Eduardo Lana da ${ }^{2}$ \\ KANESIRO, Lidiane Aparecida ${ }^{3}$ \\ BRUNINI, Maria Amália ${ }^{4}$
}

Recebido em: 2010.02.10

Aprovado em: 2010.03.04

ISSUE DOI: $10.3738 / 1982.2278-340$

RESUMO: Este trabalho teve por objetivo analisar a parceria firmada entre a Cooperativa Cooxupé e a Empresa suíça Nespresso para a produção de cafés especiais no cerrado mineiro, onde os próprios cooperados da Cooxupé são os fornecedores destes cafés. Foram aplicados questionários com questões objetivas aos produtores da cooperativa com o intuito de avaliar as dificuldades em produzir cafés especiais, de cumprirem exigências sócio-ambientais, hoje praticamente obrigatórias quando se refere a produtos de qualidade, e saber o que acham desta parceria entre sua Cooperativa e a Nespresso. A pesquisa de dados bibliográficos também foi usada para fundamentação deste estudo. Os resultados obtidos mostraram que a parceria foi aceita pelos produtores; que tal parceria tem que ser mantida e aprimorada e que se deve esclarecer os produtores da importância em se investir no meio ambiente. Para finalizar, pode-se verificar que este trabalho vem servir de embasamento para o aprimoramento da parceria entre as duas empresas envolvidas no estudo, e concluir que a parceria foi bem aceita pelos fornecedores, podendo ser aprimorada a cada ano que passa.

Palavras-chave: Cafés especiais. Cooxupé. Nespresso. Sustentabilidade. Parceria.

\section{STUDY OF CASE: PARTNERSHIP COOXUPÉ/NESPRESSO IN THE MINING SAVANNAH}

SUMMARY: This study aimed to examine the partnership between the Swiss Company Nespresso and the Cooxupé Cooperative for the production of specialty coffee in the cerrado savannah, where the ones cooperated Cooxupé are the providers of these cafes. There were applied questionnaires for some producers with objectives question to evaluate to assess the difficulties in producing specialty coffee, to meet social demands, today almost mandatory when referring to products of high quality, is, generally know what you think of this partnership between the Cooperative Cooxupé and Nespresso. A search of bibliographic data was also used for reasons of this study. The results showed that the partnership was accepted by the producers, this partnership must be maintained and enhanced and that it should clarify the producers of the importance of investing in the environment. It can be verified that this work comes to be for the improvement of the partnership among the two companies involved in the study, and to conclude that the partnership was well accepts for the suppliers, could be perfected every year.

Keywords: Specialty coffee. Cooxupé. Nespresso. Sustentability. Partnership.

\footnotetext{
${ }^{1}$ Trabalho desenvolvido como exigência para obtenção do título de Especialista em Agronegócio e Desenvolvimento Sustentável pela Faculdade Dr. Francisco Maeda-FAFRAM/FE.

${ }^{2}$ Especialista em Agronegócio do Café pela Fundação Instituto de Administração - São Paulo/FIA; Pósgraduando em Agronegócio e Desenvolvimento Sustentável pela Faculdade Dr. Francisco Maeda-FAFRAM/FE; Graduado em Administração de Empresas pelo Centro Universitário do Cerrado - Patrocínio/UNICERP. E-mail: lanacruz@bol.com.br.

${ }^{3}$ Prof. Mestre da Faculdade de Filosofia, Ciências e Letras, Fundação Educacional de Ituverava/FE e Professora do Programa de Pós-graduação da FAFRAM/FE. Rua Coronel Flauzino Barbosa Sandoval, 1259, Ituverava (SP). CEP: $14.500-000$.

${ }^{4}$ Professora Doutora e Adjunto Aposentada da Faculdade de Ciências Agrárias e Veterinárias, Campus Jaboticabal/UNESP, e Professora Doutora da Fundação Educacional de Ituverava-FE. Rua Coronel Flauzino Barbosa Sandoval, 1259, Ituverava (SP). CEP: 14.500-000.
} 


\section{INTRODUÇÃO}

Desde sua popularização por volta dos séculos XVI e XVII, a qual coincide com sua chegada à Europa, o café nunca mais deixou de estar presente na vida da maioria das pessoas. Tem grande importância na economia mundial, onde é o segundo maior gerador de riquezas, perdendo apenas para o petróleo, emprega direta ou indiretamente mais de meio bilhão de pessoas em todo o mundo (mais ou menos $8 \%$ da população mundial). O Brasil é o maior exportador mundial e o segundo maior mercado consumidor, onde o café é responsável por cerca de sete milhões de empregos, e apesar de ter diminuído sua importância na pauta de exportações ainda gera divisas da ordem de 10 bilhões de reais. (ALMANAQUE PRIDIE KALENDAS, 2008; EMBRAPA, 2008).

Mesmo sendo considerado uma commodity $^{5}$, o café vem ganhado status de specialty (especial) no mercado internacional, em razão das exigências cada vez maiores dos consumidores. Como já acontece há algum tempo com os vinhos, os apreciadores de um bom café buscam sabores específicos e únicos das mais diferentes regiões produtoras do mundo.

Atenta às mudanças na forma de consumir café, as grandes empresas do setor de torrefação e comercialização dessa matéria prima vêm investindo de forma crescente na produção e comercialização dos cafés tidos como gourmets ou especiais. São geralmente do tipo arábica $^{6}$ ou misturados (ligas) com o robusta ${ }^{7}$, sendo que, o percentual do primeiro é geralmente maior. Dentre essas empresas, o grupo Nestlé, através da Nespresso, um braço do grupo que é direcionado especificamente ao mercado de cafés especiais vêm ganhando destaque mundo afora através de um moderno sistema de venda de cafés finos, as chamadas cápsulas (café em porções).

Para que se possa produzir cafés especiais é necessário que a matéria prima seja também de alta qualidade. E, é exatamente esse um dos fatores, dentre outros, onde se destaca a empresa Nespresso, pois seus especialistas buscam os melhores grands crus $^{8}$, com diferentes sabores e aromas das melhores regiões produtoras do planeta, para que possam, assim, atender os mais exigentes e diversificados consumidores do mundo (NESTLÉ NESPRESSO, 2006).

\footnotetext{
${ }^{5}$ Expressão atribuída a bens comerciáveis, como produtos agropecuários e recursos naturais. São produtos em estado bruto ou com um grau muito pequeno de industrialização, produzidos em escala mundial e de grande importância econômica internacional, porque são amplamente negociados entre importadores e exportadores.

${ }^{6}$ Espécie de café com teor de cafeína entre 1,1\% e 1,7\%, doce, de boa acidez e originário de regiões mais altas.

${ }^{7}$ Espécie de café com teor de cafeína entre $2 \%$ a 4,5\%, mais amargo e adstringente, e originário de regiões mais baixas.

${ }^{8}$ São os melhores cafés das determinadas regiões que os originam.
} 
O trabalho de aquisição do café padrão Nespresso é feito em parcerias com empresas do setor cafeeiro de cada país ou região onde são produzidas as matérias primas. No Brasil estas compras são feitas em mais de uma região, onde se destaca a região do cerrado mineiro, cujas compras são realizadas pela Cooperativa Cooxupé ${ }^{9}$. As compras realizadas pela Cooxupé têm como fornecedores seus próprios cooperados, que são incentivados a produzirem cafés de alta qualidade, pois se estes cafés atingirem o nível de qualidade exigido pela Nespresso, recebem remuneração extra sobre o preço de mercado.

A Cooxupé tem sua sede localiza na cidade de Guaxupé, MG, sudoeste mineiro, e está presente no cerrado dos municípios de Monte Carmelo, Coromandel, Serra do Salitre e Rio Paranaíba, onde estão as cidades que originam as aquisições de cafés verdes da Nespresso na região. Segundo Barone (2007), executivo da empresa Nespresso na Suíça, "esta região foi escolhida pela altíssima qualidade dos cafés plantados e a vontade dos produtores de sempre fazerem o melhor e poderem diferenciar-se no mercado".

Outro fato marcante é que a Nespresso, que está atuando junto a Cooxupé e aos seus cooperados desde 2005, incrementou de forma não obrigatória junto aos produtores um programa de boas práticas agrícolas, denominado Nespresso AAA - Sustainable Quality Program, no qual incentiva a produção de cafés especiais, mas sem que o produtor perca o foco em questões que hoje são primordiais em qualquer setor produtivo, tais como a questão social e ambiental, ou seja, produção de forma sustentável. Por este programa, a Nespresso preza a questão do diferencial de preço, pois sem o incentivo econômico seria impossível o desenvolvimento de uma cafeicultura sustentável.

O produtor, que antes era acostumado com produções do tipo comercial, ou seja, sem nenhuma preocupação maior em relação à qualidade, começa com o advento das compras da Nespresso, a se preocupar e a mudar a forma de como produzir e a comercializar seu produto, além de enquadrar suas propriedades em um mínimo possível de normas e procedimentos usados mundialmente para uma produção sustentável.

Logo, o objetivo deste estudo foi analisar a relação de aproximação que o grupo Nespresso desenvolve junto aos produtores de café da região do cerrado mineiro, que conta com o intermédio da cooperativa Cooxupé.. Também, neste estudo tenta-se mostrar o que pensa o produtor com a parceria firmada entre sua cooperativa, a Cooxupé, e a subsidiária do grupo Nestlé, a Empresa Suissa Nespresso, se a remuneração extra recebido referente à qualidade do grão de café é compensatória, onde esta remuneração tem sido empregada, o desenvolvimento do Programa AAA, e outras questões que o envolve esta parceria.

${ }_{9}^{9}$ Cooperativa regional de Cafeicultores em Guaxupé Ltda. 


\section{REVISÃO DA LITERATURA}

Devido a melhoria na qualidade de vida de milhões de pessoas mundo afora, que vem acontecendo desde o fim da década de 80, fruto de uma conspiração de vários fatores econômicos, o atributo qualidade vem ganhando destaque a cada dia que passa em todos os setores da economia, principalmente na indústria de alimentos, não sendo diferente o que vem ocorrendo com a indústria cafeeira. Um dos principais feitos que as conquistas econômicas possam originar, é a melhoria na qualidade dos produtos consumidos, principalmente na indústria alimentícia.

Porém, em setembro de 2008, o mundo foi surpreendido por uma enorme crise financeira, que teve início no setor imobiliário americano, e se espalhou por todo o mundo. Mas, segundo diversos especialistas, os principais países a escaparem com menores prejuízos à crise serão os emergentes, e mais, os que têm uma base sólida nas exportações de produtos alimentícios levarão maiores vantagens, pois a demanda por alimentos no mundo é grande, principalmente por parte dos países emergentes, que mesmo apresentando desaceleração no crescimento, devem continuar crescendo e comprando alimentos de outros países (FRARE, 2009). Notadamente, os produtos agropecuários sofrem menos a ação de crises financeiras, pois os mesmos são considerados de primeira necessidade, e entre os produtos agropecuários, o café, consumido mundo afora há mais de dois séculos, é considerado por aqueles que o apreciam como um alimento vital as necessidades do ser humano no dia a dia. O que se observa em meio a turbilhões financeiros, como o que se vivencia atualmente, é uma troca de hábitos de tomar café, como por exemplo, as substituições das visitas freqüentes dos consumidores às casas de café (cafeterias) pelo consumo doméstico (ILLY, 2009).

Com essa mudança de hábito, a Nespresso, em parceria com grandes fabricantes de eletrodomésticos, é hoje uma das líderes mundiais na venda de máquinas para consumo de café espresso nos lares. Todos os que adquirem uma máquina de café Nespresso para suas casas, automaticamente se tornam membros do "Nespresso Club", que tem um serviço personalizado, o qual fornece uma grande variedade de informações, aconselhamento e serviços sob medida sobre o café e as máquinas Nespresso, além de muitos outros benefícios (NESTLÉ NESPRESSO, 2006). Sabendo que em tempos de intempéries econômicos, costuma ocorrer uma migração dos consumidores de café superiores das cafeterias para o consumo doméstico, a crescente venda de máquinas de café espresso da empresa suíça para uso nos lares, pode ser mais um diferencial a seu favor em relação aos concorrentes e ao seu próprio crescimento em tempos de recessão. 


\section{COOPERATIVA COOXUPÉ}

Na busca de sobrevivência à crise de 1929 com a queda da bolsa de Nova York, em 19 de novembro de 1932 foi criada, por 24 produtores rurais, uma cooperativa de crédito, que em 27 de novembro de 1957 ela foi transformada em cooperativa de produção, hoje a conhecida mundialmente Cooxupé. Essa cooperativa conta uma matriz em Guaxupé, MG, e mais quinze filiais, que estão distribuídas entre as regiões do sudoeste mineiro, mogiana paulista e cerrado mineiro, uma trading ${ }^{10}$ em Poços de Caldas/MG, escritório de exportação em Santos/SP e mais de 11.500 cooperados e 1.880 funcionários.

Em Serra do Salitre, MG, onde este estudo foi realizado, as instalações da Cooperativa Cooxupé iniciaram em meados de setembro de 2002, com a abertura da loja de insumos, assistência técnica, classificação de cafés e o aluguel de um barracão para armazenagem de café.

Sabendo que para a produção de cafés superiores, a Nespresso precisaria de matérias primas de elevada qualidade, a Cooperativa Cooxupé cria um sistema de $\operatorname{compras}^{11}$ que privilegia aqueles produtores que buscam a produção destes grãos de café. Junto a um método diferenciado de aquisição de cafés, a empresa suíça busca despertar, perante o produtor, a produção de forma consciente, levando as fazendas de café do cerrado mineiro os conceitos de produção sustentável, já antes conhecido, mais pouco praticado pelos produtores. Com isso, ela visa não só a produção de um dos melhores expresso do mundo, como também presa o respeito ao meio ambiente, às pessoas e comunidades onde estão inseridas as fazendas que produzem estes cafés. Dizia Knutsen (2009), tradicional importadora de café finos da região de San Francisco, Califórnia, "muitas vezes o que torna o café especial não é tanto o produto, mais a afetividade que ele evoca como fruto de um relacionamento estável".

\section{PARCERIA COOPERATIVA COOXUPÉ E A EMPRESA SUISSA NESPRESSO}

Ligado a esse novo rearranjo nas mudanças econômicas mundiais, o grupo Nestlé resolve, em 1986, investir maciçamente na qualidade de cafés. Com isso surge, em Vevey na Suíça, a Nespresso, subsidiária do grupo destinada à produção de cafés finos, com um moderno e inovador sistema de café em porções (cápsulas), ou seja, cada embalagem vem pronta e destina-se a produção de um expresso.

Segundo especialistas da Nespresso, apenas $10 \%$ da produção mundial de café são

\footnotetext{
${ }^{10}$ Empresa de negociação (aquisição) de cafés de não cooperados, pois através da cooperativa, a Cooxupé só pode adquirir café de seus cooperados, o que limita o seu raio de ação.

${ }^{11}$ É a aquisição de café feita pela Nespresso, junto aos cooperados da Cooxupé, que devem atender a um padrão mínimo de qualidade exigido pelo grupo Nestlé, e com isso recebem um prêmio (em dinheiro) por estes cafés.
} 
considerados especiais ou gourmets, e dessa fração, apenas de $10 \%$ a $20 \%$ têm a qualidade exigida pelos padrões Nespresso. Somado à qualidade dos cafés, a Nespresso desenvolve máquinas inteligentes que são específicas para suas cápsulas e por fim incomparáveis serviços personalizados, formando assim a chamada trilogia Nespresso ou seja, os três pilares da excelência. Segundo Rodrigues (2009), a trilogia Nespresso é composta pelas variedades de café de alta qualidade; máquinas de design elegante dotadas de funções adicionais como leite fresco, cappuccino e água quente; e o melhor serviço personalizado através do Clube Nespresso. Este modelo não para de crescer mundo afora, e cada vez mais é necessária à aquisição de cafés especiais para suprir a crescente demanda. É, quando surge, em 2005, à parceria Cooxupé/Nespresso no cerrado mineiro, região escolhida pela excelente bebida de seus cafés. Segundo Assessor da Faemg ${ }^{12}$, engenheiro Agrônomo Rodrigo Ponte ${ }^{13}$ esta região $^{-}$ tem certas particularidades que permite a colheita em período seco, diferente de outros locais, além de que sua altitude, temperatura e distribuição de chuvas dão um sabor único ao produto final.

A parceria Cooxupé/Nespresso, que teve início há pouco tempo, vem mudando gradativamente os conceitos até então enraizados na cafeicultura da região do cerrado mineiro.

Em apenas dois anos, através dos dados de comercialização, relativos à filial de Serra do Salitre, MG, pode-se verificar o grande interesse dos cooperados da Cooperativa Cooxupé em aderirem ao programa de preparo e venda de cafés para o grupo Nespresso. Pelos dados apresentados na Figuras 1, pode-se observar que, o volume comercializado para a Empresa Nespresso do ano de 2006 ao ano de 2007, aumentou de $10 \%$ para $29 \%$.

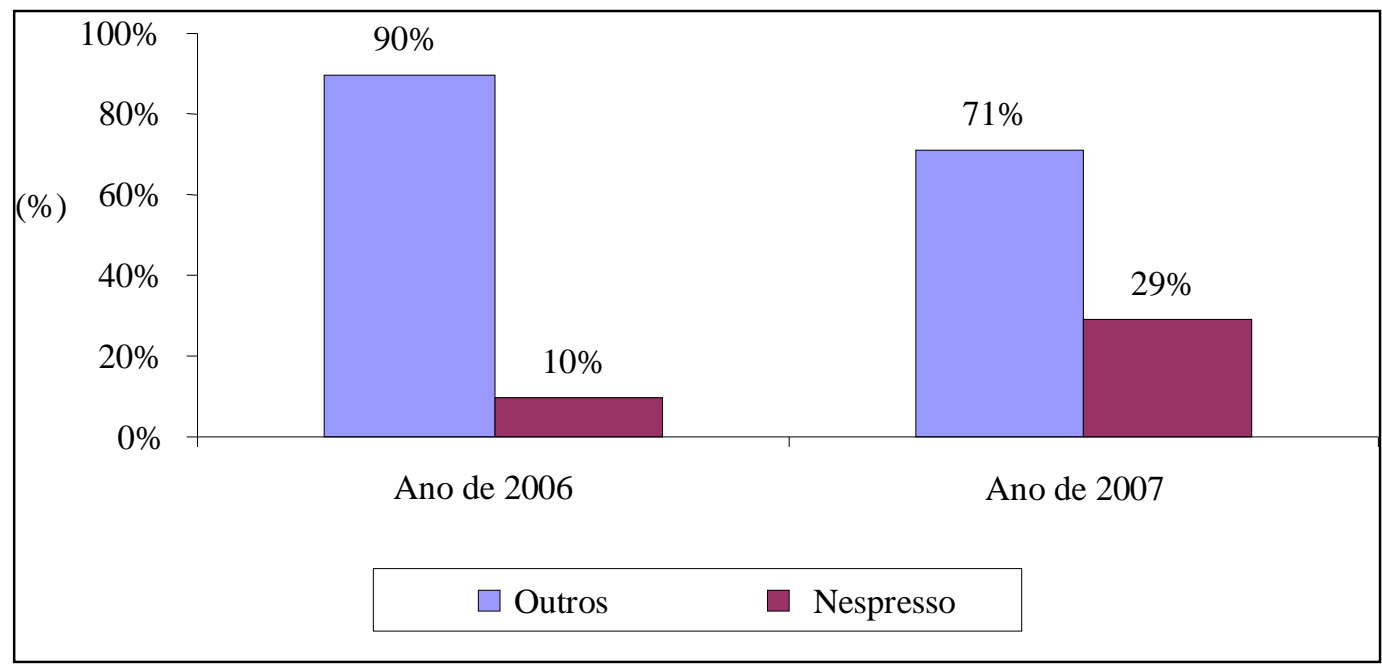

Figura 1: Café comercializado pela Cooperativa Cooxupé de Serra do Salitre (MG), nos anos de 2006 e 2007.

\footnotetext{
${ }^{12}$ Federação da Agricultura e Pecuária do estado de Minas Gerais.

${ }^{13}$ Comunicação Verbal.

Nucleus, v.7, n.1, abr. 2010
} 


\section{METODOLOGIA}

Devido ao elevado número de produtores fornecedores da Cooperativa Cooxupé, que abrange uma grande região do cerrado do estado de Minas Gerais, este trabalho refere-se somente ao município de Serra do Salitre, MG, onde do ano de 2007 ao de 2008, ocorreu um aumento de 37 para 106 participantes, isto é de produtores que aderiram ao sistema de compras Nespresso de café especiais.

Esse estudo foi realizado de março de 2008 a abril de 2009 e os dados foram coletados de abril e julho de 2008, que de acordo com Barbetta (2002) caracteriza-se como uma pesquisa probabilística e intencional. A amostragem correspondeu a todos os produtores que forneceram café tanto em 2007 quanto em 2008, que perfizeram um total de 28 produtores, que responderam um questionário com dezesseis perguntas fechadas (objetivas) em relação à parceria Cooxupé/Nespresso. A maioria das perguntas tinha respostas diretas e objetivas, e de fácil compreensão aos respondentes. O questionário abordava itens sobre a parceria produtor, cooperativa e a empresa suíça; a remuneração extra recebido pelo café especial, onde ou em como era investida esta remuneração; a possibilidade de aprimoramento da parceria entre a cooperativa e a subsidiária do grupo Nestlé; o programa AAA de sustentabilidade, a dificuldade na produção de cafés gourmet no padrão Nespresso pelos produtores e dados referentes à produção dos cooperados.

Antecedendo a aplicação dos questionários foi solicitada oficialmente autorização prévia dos dirigentes responsáveis tanto da Cooperativa Cooxupé quanto da Empresa Suissa Nespresso, e somente depois iniciado a aplicação dos questionários. Os questionários foram distribuídos a todos os 28 produtores, que tiveram uma semana de prazo para preenchimento, tendo sido tomado o máximo de cuidado para a não identificação dos participantes, e o cuidado de considerar que as pessoas que responderam aos questionários representassem os próprios cooperados da Cooxupé selecionados para este estudo.

Também, foi realizado levantamento de dados secundários com pesquisa bibliográfica, pois a fundamentação teórica se baseou em material publicado em livros, em revistas especializadas, em comunicação verbal e em internet.

Os dados obtidos foram codificados, digitados em planilha eletrônica, em forma de banco de dados (Excel for Windows), distribuídos em gráficos e analisados qualitativa e quantitativamente.

\section{RESULTADOS E DISCUSSÃO}

\section{Da parceria}


Os entrevistados quando abordados sobre o que acham da parceria entre Cooxupé e Nespresso, dos 28 entrevistados, $64 \%$ responderam que acham a parceria muito boa, $36 \%$ boa, e pelos resultados obtidos pode-se verificar que ninguém desaprova a parceria firmada entre as duas empresas (Figura 2). Quando perguntados se acreditam que de alguma forma a comunidade é beneficiada com a Parceria, $100 \%$ dos produtores entrevistados foram unânimes em responder que sim.

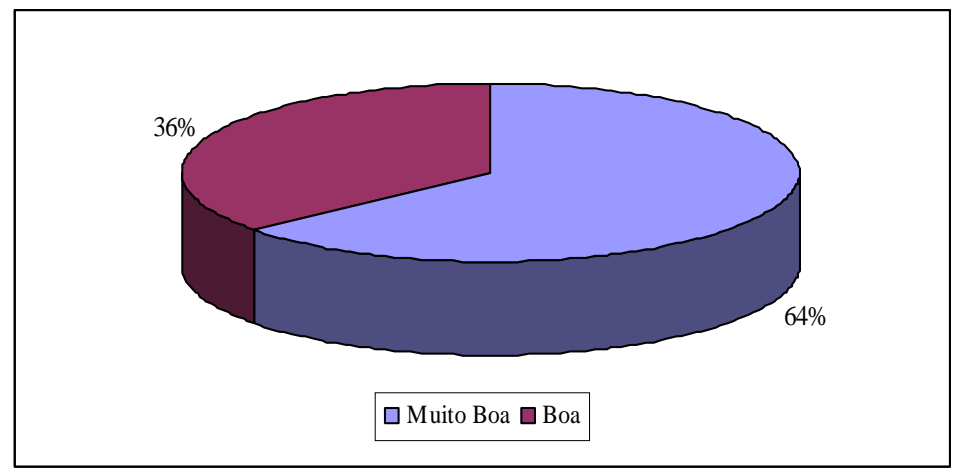

Figura 2: O que você acha da Parceria entre a Nespresso e a Cooxupé?

Os cooperados, ao serem abordados sobre se é válido a comunidade saber dos benefícios adquiridos pelos produtores com o advento da união Cooxupé e Nespresso, observa-se pelos dados, na Figura 3, que a maioria $(96,5 \%)$ acha interessante repassar as informações.

Os produtores ao serem indagados sobre se a produção de café de altíssima qualidade com sustentabilidade é algo promissor, 96,5\% dos entrevistados responderam que a mesma tem característica para durar, enquanto que 3,5\% disseram que os resultados virão em médio prazo (Figura 3), e nenhum produtor disse que a parceria teria resultados passageiros, mostrando assim um grande otimismo por parte dos cooperados em relação ao sistema de compras.
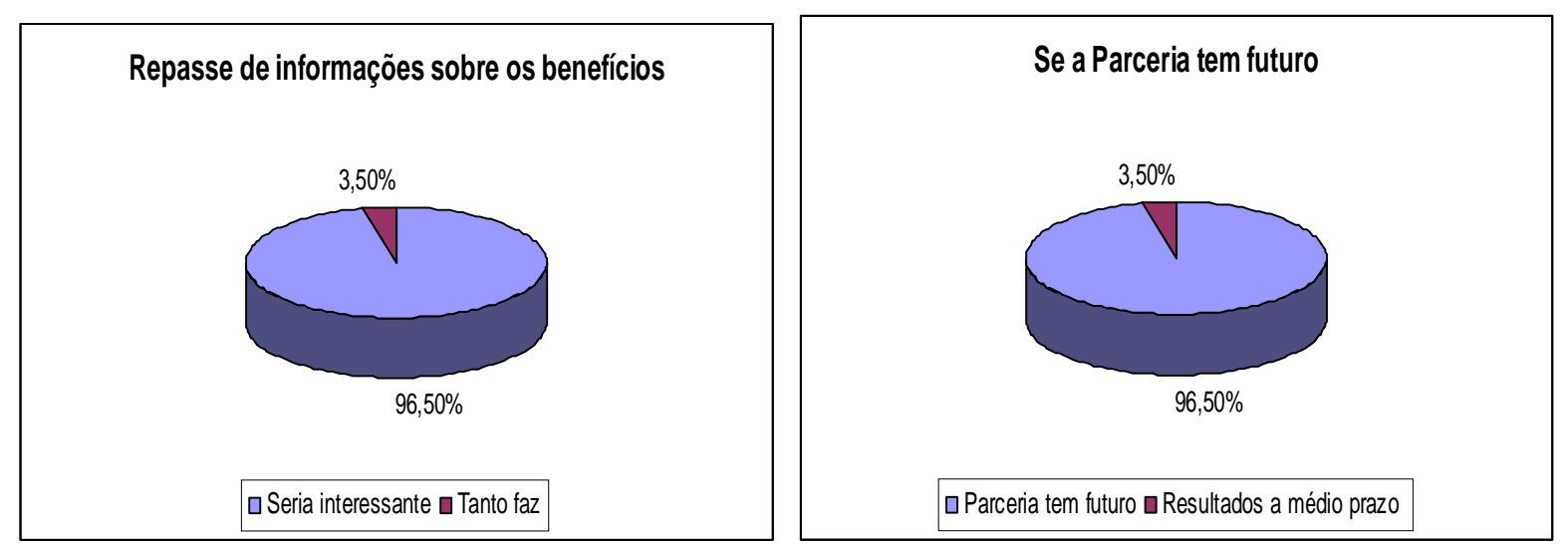

Figura 3: Você acha que seria interessante a comunidade saber os benefícios que a Parceria Nespresso e Cooxupé tem ocasionado aos produtores? Acha que tal Parceria tem futuro promissor? 


\section{Destino da Remuneração Extra Pago ao Produtor}

Considerando o destino da remuneração extra pago ao produtor como um dos itens mais importantes desta avaliação, pois a mesma define os rumos da aplicação dos recursos obtidos com a venda dos cafés "superiores" foram feitas varias perguntas aos produtores. Primeiro os entrevistados foram questionados sobre ser ou compensatório o prêmio extra pago ao produtor por estes cafés gourmets, onde se pode verificar que $86 \%$ responderam ser válido o prêmio, e apenas $14 \%$ responderam que não (Figura 4), o que mostra a satisfação dos cooperados da Cooperativa Cooxupé com o recebimento de remuneração extra.

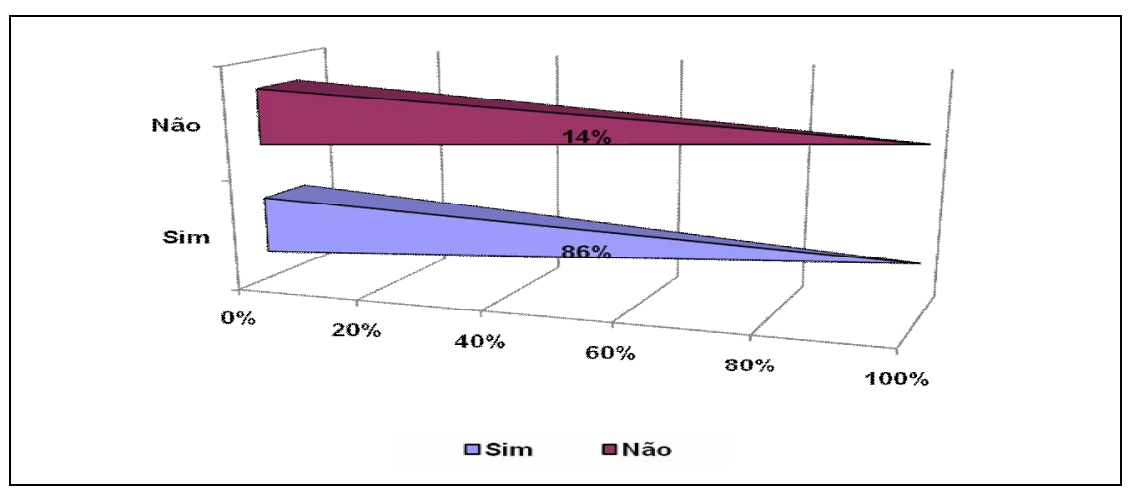

Figura 4: Satisfação quanto ao prêmio pago.

Ainda, com relação ao prêmio extra, foi perguntado aos cooperados o destino que era dado ao referencial recebido pelo fornecimento do grão com a qualidade dos grãos para fabricação de café gourmet, onde se pode verificar que $93 \%$ reinvestem o prêmio de volta na propriedade (Figura 5), e somente 3,5\% aplicam os recursos na educação dos filhos e melhorias para si próprios.

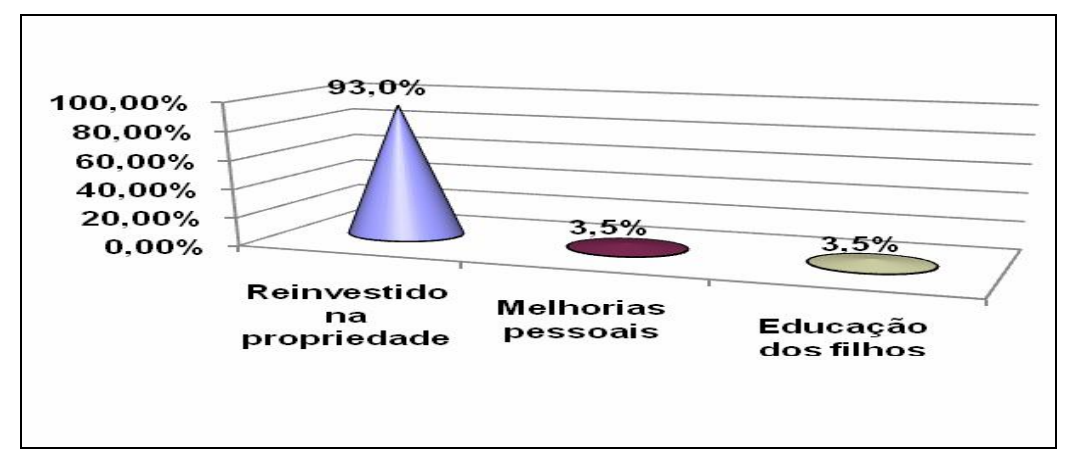

Figura 5: Destino dos recursos do prêmio extra recebido.

Os entrevistados ao serem abordados sobre o reinvestimento na propriedade a maioria dos cooperados que responderam este item, $81 \%$ responderam que o capital ganho com o diferencial de preço é voltado a buscar melhorias na qualidade dos cafés, enquanto 
$15 \%$ reaplicam em melhorias ambientais, e apenas $4 \%$ reinvestem o prêmio nos seus colaboradores/funcionários (Figura 6).

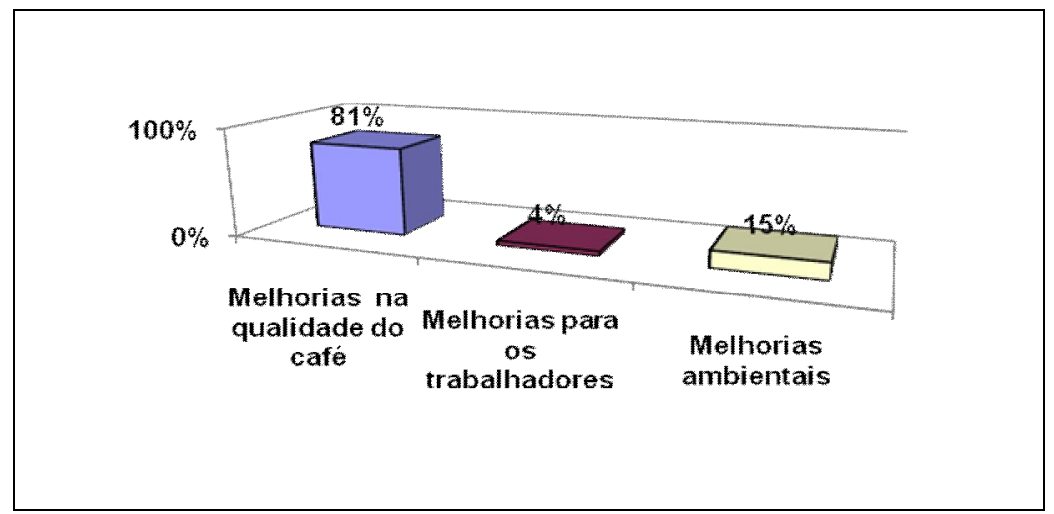

Figura 6: Como você distribui o prêmio extra na fazenda?.

Tomando como referência a aplicação dos recursos na propriedade (Figura 6), os entrevistados foram indagados como investem na melhoria da qualidade do café. A maioria, 95\% deles responderam que reinvestem em construção de terreiros de secagem, tulhas e secadores mecânicos, 5\% reinvestem em processos para obtenção de certificações, e nenhum na formação de lavouras com novos cultivares (Figura 7).

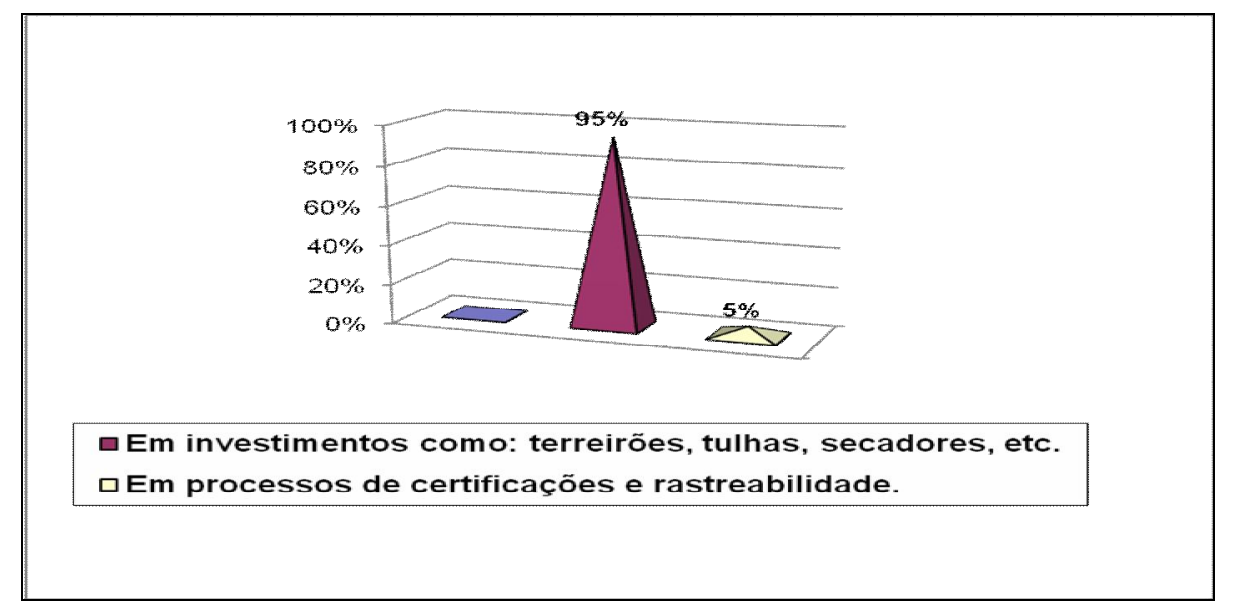

Figura 7: Como investem na melhoria da qualidade dos cafés

Dos $15 \%$ que responderam investir em melhorias ambientais, $100 \%$ responderam que buscam se adequar as leis ambientais em vigor no país, e dos $4 \%$ que responderam que investem em melhorias para os trabalhadores, $100 \%$ dos opinantes responderam que quando investem nos trabalhadores, é diretamente em melhorias salariais (Figura 8).

\section{Aprimoramento da parceria e o programa AAA de Sustentabilidade}

Presente na Nespresso desde o ano de 2003, o programa AAA de produção sustentável 
de cafés mesmo não sendo de uso obrigatório é cada vez mais aceito e empregado pelos produtores.
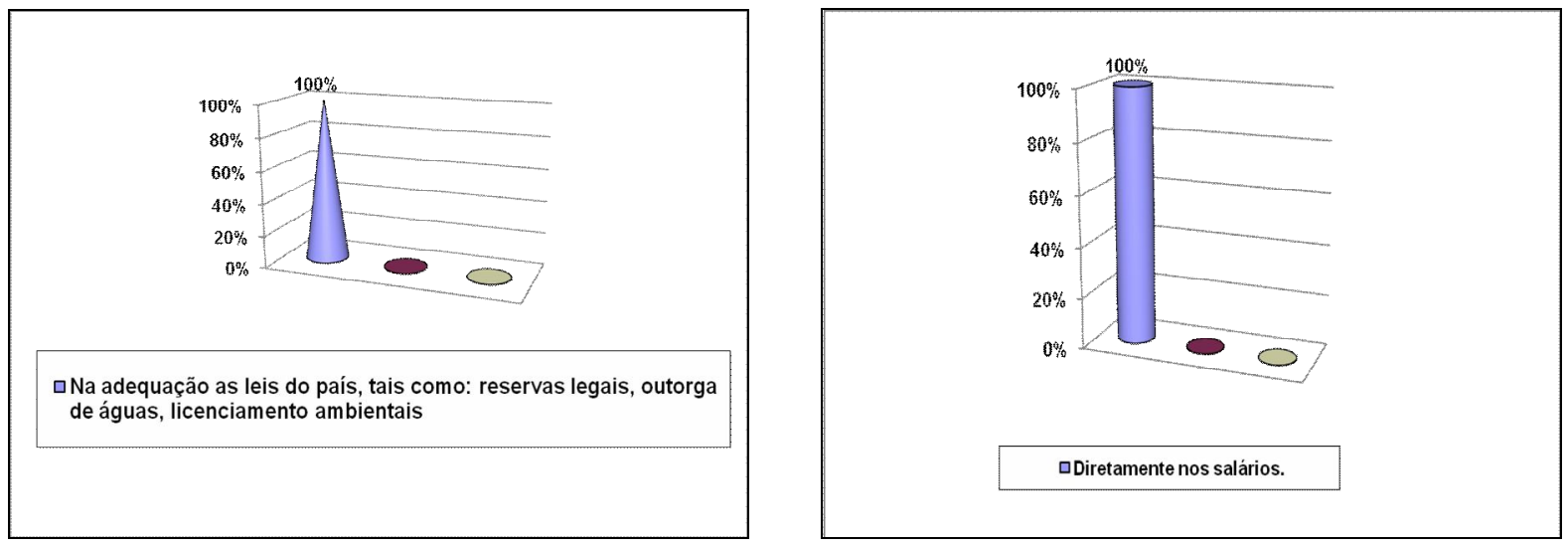

Figura 8: Melhoria ambiental e melhoria para os trabalhadores.

Os entrevistados foram perguntados, se eles realmente acreditam que a Nespresso visa a produção de cafés de modo ssutentável e se os ganhos podem de certa forma viabilizar esta "nova cafeicultura", e do total dos produtores entrevistados 71,5\% acreditam que a Empresa suissa Nespresso visa produção sustentável e 28,5\% acham que esta produção é parcialmente sustentável (Figura 9).

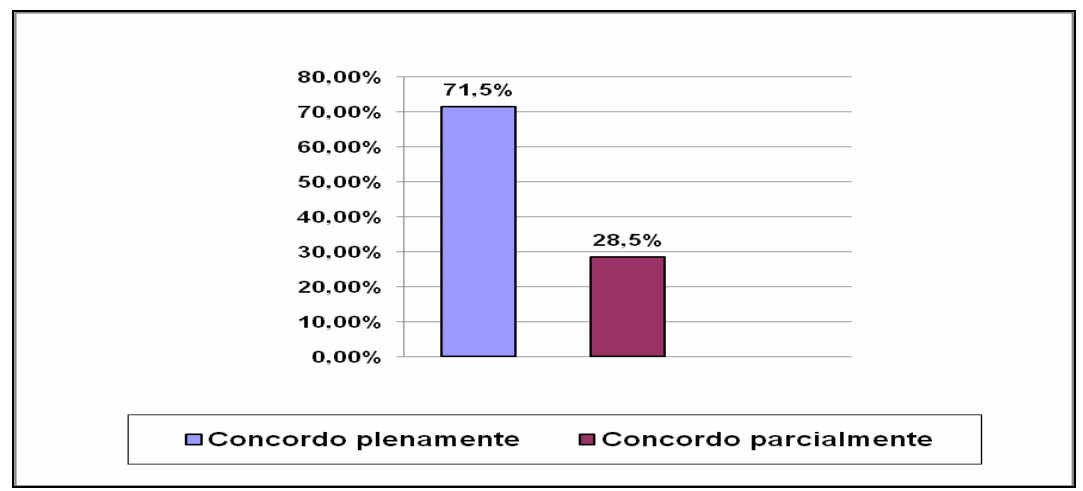

Figura 9: Você acha que Nespresso visa produção de café sustentável?

Também, foi perguntados aos entrevistados se parceria Cooxupé/Nespresso e os produtores poderia ser melhorada através de palestras, dia de campo, semináriso. Através dos dados obtidos pode-se verificar que $86 \%$ responderam que sim e $14 \%$ responderam que concordam parcialmente com essas atividades (Figura 10).

Os entrevistados, ao serem entrevistados se a parceria entre Cooxupé/Nespresso deve ser mantida e até mesmo aprimoradae todos os entrevistados responderam que sim, isto é deve ser mantida e melhorada. 


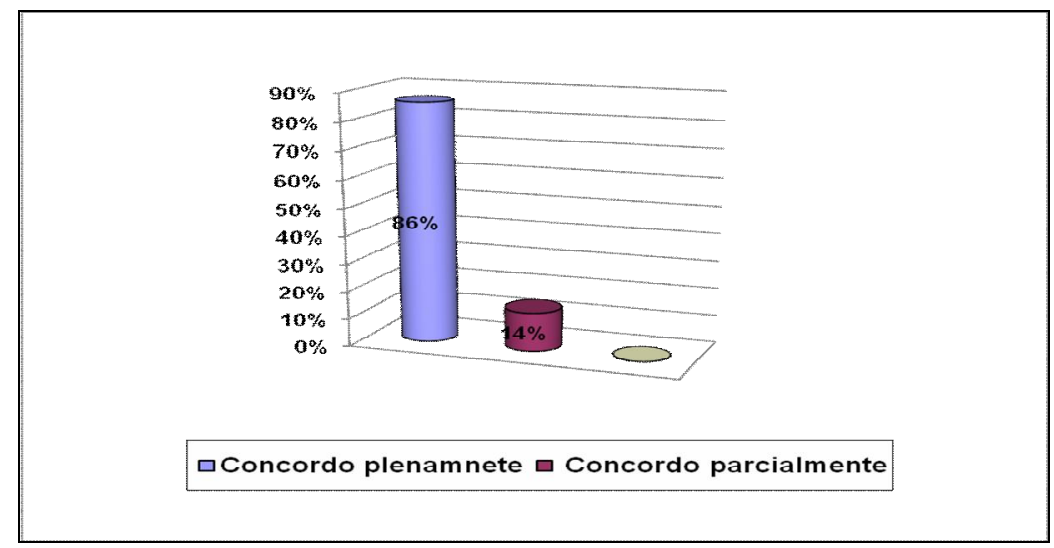

Figura 10: Como melhorar a parceria Cooxupé/Nespresso e os produtores.

\section{Dados da Produção}

Os resultados obtidos a respeito da produção de café pelos cooperados da Cooxupé, podem se tornar importantes para futuras tomadas de decisões sobre a parceria Nestlé/Cooxupé. Neste estudo, através dos dados da Figura 11, pode-se verificar que há produtores de portes diferentes em relação à produção e, conseqüentemente área cultivada, o que pode implicar em estratégias diferentes para se atingir cada um deles.

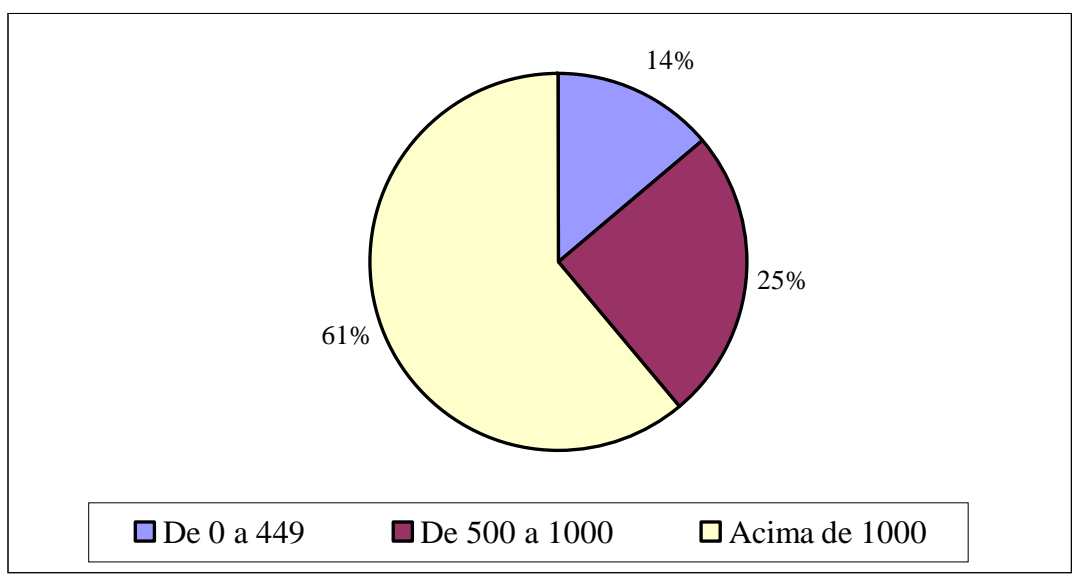

Figura 11: Qual a quantidade média de sacas, de $60 \mathrm{~kg}$, de café foram produzidas na ultima safra?

Os entrevistados ao serem questionados se do quanto do total colhido de café na última safra (Figura 11), quanto eles haviam fornecido a Empresa Nespresso pode-se verificar que a maioria dos produtores conseguiram entregar mais de $75 \%$ da produção ao sistema de compras da Cooxupé/Nespresso (Figura 12), o que mostra o enorme potencial da região na produção de cafés especiais. 


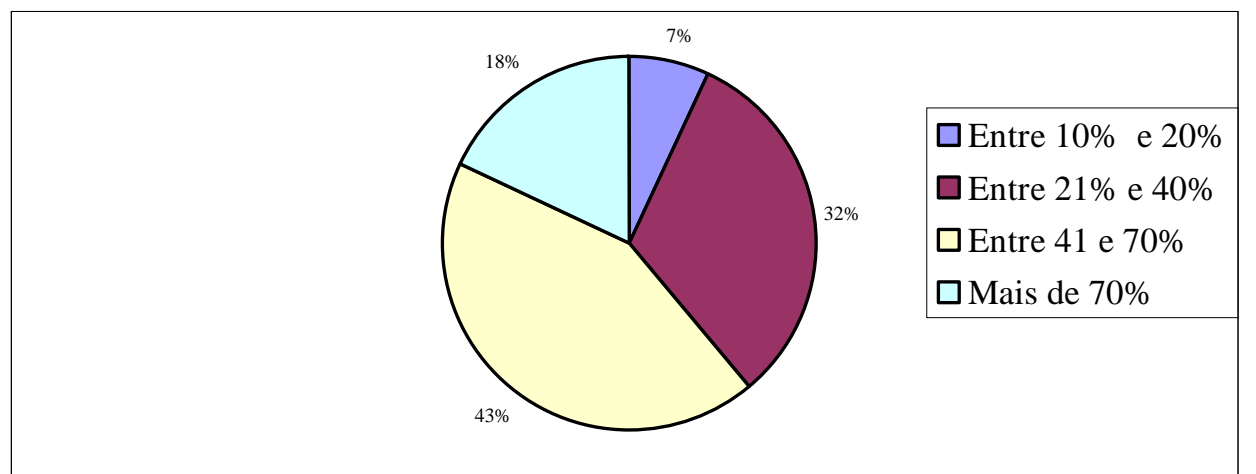

Figura 12: Porcentagem de cafés entregues a Nespresso em relação à produção total de grâos.

Outro fato interessante, apesar do pouco tempo de existência da parceria entre as empresas, foi quando perguntados se era complicado a produção de cafés no padrão Nespresso. Neste item os produtores foram de um extremo a outro (Figura 13), onde 50\% acham difícil, apenas 3,5\% acham muito difícil, e o que mais chamou a atenção, 46,5\% responderam ser fácil a produção deste tipo de café; que pode ter como uma justificativa para esta resposta o clima propício que esta região tem, pois praticamente não chove na época da colheita dos grãos de café, além da baixíssima umidade relativa do ar, o que evita a proliferação de fungos, que é um dos fatores que mais afetam a qualidade final do produto.

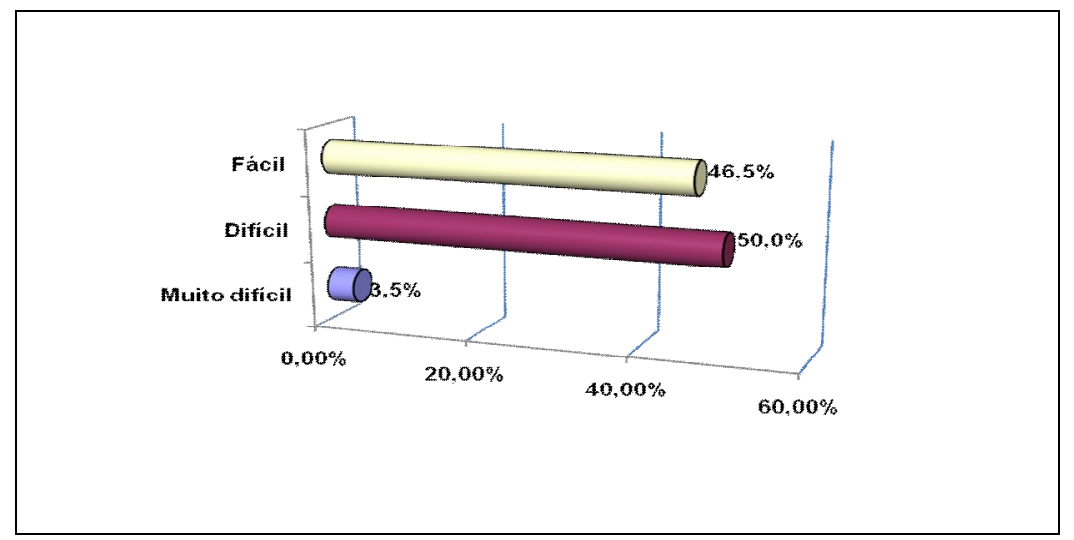

Figura 13: Como acham ser a produção de café no padrâo Nespresso.

\section{CONSIDERAÇÕES FINAIS}

Analisando os resultados desse estudo, observa-se de um modo geral, que há um grande entusiasmo por parte dos produtores, com relação à parceria firmada entre a sua cooperativa, a Cooxupé, e a empresa suíça, a Nespresso. As respostas obtidas indicam que a união das duas, visando à aquisição de cafés finos e sustentáveis, deve não só ser mantida como também aprimorada. 
Sendo recente a parceria em Serra do Salitre - MG, um dos fatores que pode ser melhorado, é o esclarecimento junto aos cafeicultores da importância da relação deles com o meio ambiente e das adequações sociais, as quais hoje são muito requisitadas pelos consumidores finais. Quanto à Nespresso AAA- Sustainable Quality Program, nota-se uma grande preocupação por parte dos produtores, em melhorar e até aumentar a produção de cafés do padrão Nespresso, com investimentos em terreiros de seca, tulhas e secadores mecânicos, enquanto as exigências sócio-ambientais são deixadas para segundo plano.

Apesar da parceria entre as empresas Cooxupé e Nespresso ter sido surpreendida, atualmente, pela enorme crise financeira que se abateu no mundo, setores como os de alimentos são menos vulneráveis as dificuldades econômicas, onde se inclui o café, pois mesmo em meio a intempéries financeiros, os apreciadores de um bom café, praticamente não diminuem o consumo, tendo em vista que o que muda são os hábitos, passando o consumo a ser mais doméstico. Sendo assim, este cenário nebuloso pode se tornar um diferencial a favor da empresa suíça, já que a maioria das vendas de seus produtos são para consumo no lar.

O mais relevante dos aspectos analisados na pesquisa, foi a remuneração extra pago pela empresa do grupo Nestlé aos cooperados que produzem cafés superiores, além de beneficiar produtores dos mais variados tamanhos, ainda ajuda a melhorar a distribuição do PIB da cadeia do café, cada vez mais desfavorável aos países produtores, como pode ser observado na Tabela 1.

Tabela 1: PIB Mundial do Café

\begin{tabular}{l|c|c|c|c}
\hline \multicolumn{5}{c}{ PIB do Café: Distribuição do valor na cadeia produtiva } \\
\hline & $\begin{array}{c}\text { Ano 1991 } \\
\text { (US\$ Bilhões) }\end{array}$ & $\begin{array}{c}\text { Percentual } \\
1991\end{array}$ & $\begin{array}{c}\text { Ano 2001 } \\
\text { (US\$ Bilhões) }\end{array}$ & $\begin{array}{c}\text { Percentual } \\
2001\end{array}$ \\
\hline Países Produtores & 9,0 & $30 \%$ & 9,0 & $10 \%$ \\
\hline Países Consumidores & 21,0 & $70 \%$ & 81,0 & $90 \%$ \\
\hline Total (US\$ Bilhões) & 30,0 & -- & 90,0 & -- \\
\hline Total Percentual & -- & $100 \%$ & -- & $100 \%$ \\
\hline
\end{tabular}

Fonte: TEIXEIRA (2009)

Para finalizar, pode-se concluir que a parceria foi bem aceita pelos fornecedores, podendo ser aprimorada a cada ano que passa, buscando estreitar os laços entre as empresas parceiras e o produtor, e porque não com o consumidor final, levando assim, às xícara dos mais diversos consumidores mundo afora, não só um produto de extrema qualidade como também de afetividade (relacionamento). 


\section{REFERÊNCIAS}

BARBETTA, P. A. Estatística aplicada às ciências sociais. 5. ed. Florianópolis: UFSC, 2002 .

BARONE, P. A Nespresso no cerrado. Informação, 2007. 1p.

FRARE, J. Alcides Amaral (ex-Citibank) analisa crise mundial. Disponível em: <htpp://www.cafepoint.com.br> . Acesso em: 17 mar. 2009.

ALMANAQUE PRIDIE KALENDAS. Café um esboço histórico- Já foi conhecido como o vinho do islã. Disponível em <http://www.calendario.cnt.br/cafe.htm>. Acesso em: $12 \mathrm{dez}$. 2008.

EMBRAPA-EMPRESA BRASILEIRA DE PESQUISA AGROPECUÁRIA. Consorcio brasileiro de pesquisa e desenvolvimento do café. Disponível em: $<$ http://www. embrapa.br/café>. Acesso em 30 de out. 2008.

ILLY, A. O mercado internacional de café. Revista L'espresso, São Paulo, v. 24, 2009. p. 19, maio 2009.

KNUTSEN, E. Compreendendo os cafés especiais. Disponível em:

<htpp://coffeetraveler.net>. Acesso em: 03 mar. 2009.

NESTLÉ NESPRESSO S.A. A experiência suprema em café. Documento interno, 2006. $10 \mathrm{p}$.

RODRIGUES, C. Nespresso com sistema de pagamento. Disponível em:

$<$ http://www.hipersuper.pt/2008/11/13/gemini-tower-com-sistema-de-pagamento/>. Acesso em: 11 nov.. 2009.

TEIXEIRA, M. Brasil e Colômbia pedem fatia mais justa nos lucros do café. Disponível em: 〈htpp://www.revistacafeicultura.com.br>. Acesso em: 12 fev. 2009. 
